\title{
ENHANCING THE URBAN QUALITY OF LIFE: A CASE STUDY OF A COASTAL CITY IN THE METROPOLITAN AREA OF ROME
}

\author{
FABRIZIO CUMO ${ }^{1}$, FRANCESCA ROMANA CURRELI ${ }^{1}$, ELISA PENNACCHIA ${ }^{1}$, \\ GIUSEPPE PIRAS ${ }^{2}$ \& ROSSELLA ROVERSI ${ }^{1}$ \\ ${ }^{1}$ CITERA, Sapienza University of Rome, Italy \\ ${ }^{2}$ DIAEE, Department of Astronautical, Electrical and Energy Engineering, Sapienza University of Rome, Italy
}

\begin{abstract}
The present paper concerns an environmentally sustainable neighborhood planning project, as part of the smart community, located in the municipality of Ladispoli, in the Metropolitan area of Rome, along the Tyrrhenian coast. The project was designed as a solution to two current issues, involving all the major urban areas of the Northern Hemisphere: the ageing population and the young New Immigrants Citizens integration; the purpose is, therefore, to create an intergenerational space of mutual support and exchange among the local residents. The latter includes residential buildings NZEB (net zero-energy building) that are eco environment-friendly, designed with new building technologies based on the reuse of the main municipal solid waste, facilities minimization and the integration of renewable energy sources. The complete utilization of the local waste production in order to realize modules with low environmental impact is a key requirement to increase the overall environmental sustainability of buildings. An additional distinctive feature of this proposition is linked to the requirement of the dwelling flexibility, enabling those who live in it to easily adapt the apartments to their changing needs during a lifetime, also facilitating the integration among the different generations. The common thread of sustainability involves not only the housing project but also the dimension of a wider space, where green space plays a key role. Urban greenery is not by itself a boundary line between areas and activities, but attempts to re-establish equilibrium and natural functions that are essential for citizens' quality of life. The residential complexes are inserted in a planimetric urban design with leaflike shape and functions; some of the strong points of this project are the use of local and renewable resources, the use of active systems for energy production and passive technologies to reduce $\mathrm{CO}_{2}$ emissions, and the improvement of air-quality-enhancing green spaces.
\end{abstract}

Keywords: environment, NZEB, age-friendly, upcycle, FER, sustainable development, coastal zone management, built environment, quality of life, floating port, urban planning.

\section{INTRODUCTION}

Ladispoli is a coastal town of about 41,000 inhabitants [1] (Fig. 1). From a touristic point of view, it is strategically located, as it lays approximately $30 \mathrm{~km}$ far from both Civitavecchia and Rome, to which it is well connected by rail, and the regional and interregional bus COTRAL.

Ladispoli was part of Southern Etruria, and is therefore an area rich in history. Here we find necropolis, Roman villas, castles, ancient roads and houses, as well as historical heritages. Originally named Alsium, it was first the port of nearby Etruscan Caere, of mythical Pelasgic foundation; the city of Ladislao, was founded in 1888 at the behest of Prince Ladislaus Odescalchi that assigned part of his estate of Palo, between the ditches and Vaccina Sanguinara, to create a new beach resort on his lands. It is a small fishing village that, in just over a century, has been transformed into a modern touristic city.

In October 2014, Ladispoli signed an agreement for the promotion of the historical and natural riches of Southern Etruria. 


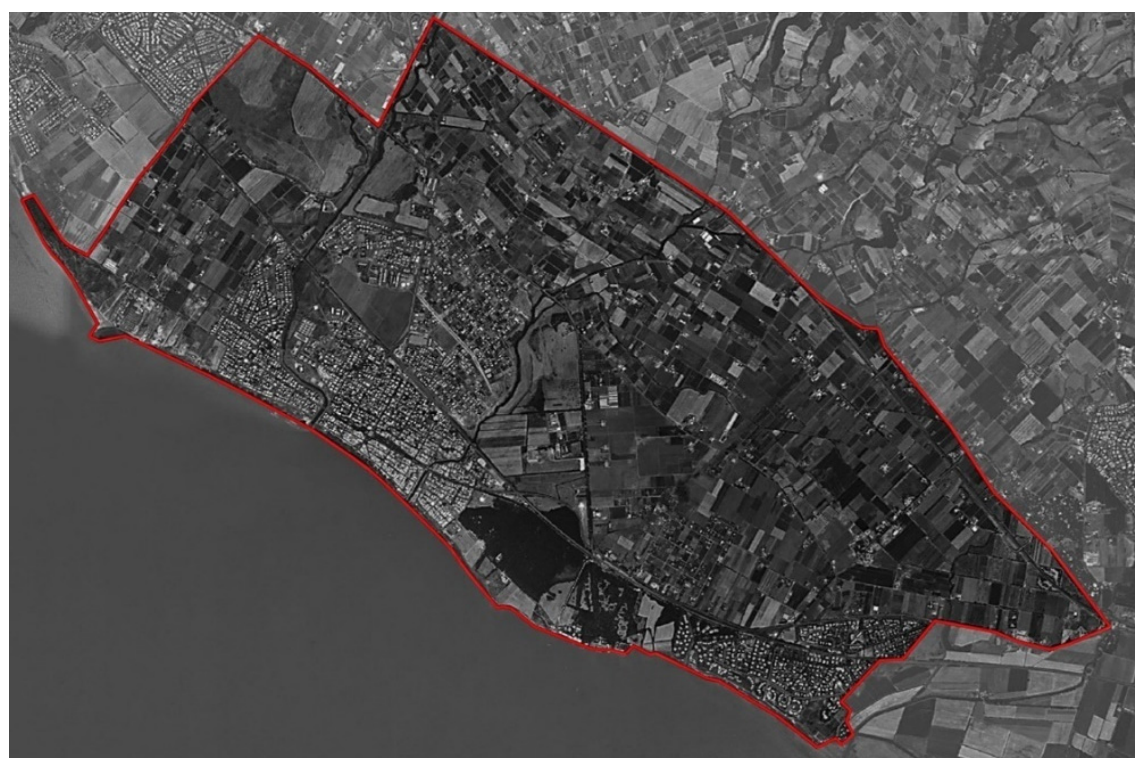

Figure 1: Administrative boundaries of the municipality of Ladispoli, in region of Lazio, central Italy.

Despite its history, architectural, and natural riches, the tourist infrastructure of these beach resorts are insufficient and a project to supplement them has therefore been designed.

The most obvious deficiency is the lack of a marina and the absence of direct and sustainable connections between the urban fabric and the reserved space for the beaches and protected natural area of Torre Flavia Swamp that since 1997 is a Special Protection Area (SPAs). The opportunity to redesign a sustainable residential expansion area for social purposes, destined to the most vulnerable sections of the population, such as the elderly and immigrant young couples, can "patch up" the territory and solve the abovementioned issue.

In fact, it would link the largely agricultural hinterland of the municipality with the coast, which has been increasingly subject to anthropic pressure, due to massive tourism from the metropolitan area of Rome.

\section{THE DESIGN OF AN “AGEING FRIENDLY” ZERO-ENERGY NEIGHBORHOOD}

The concept of the garden city, that was considered the future in the 19th century, can be nowadays be used as a model for urban agglomerations and for sustainable neighborhoods, thanks to the use of new technologies that allow to update and strengthen its design. In the case of Ladispoli, the available area is an area of about 65 hectares of land, as in the Master Plan, and is designed for a sustainable neighborhood (Fig. 2).

The housing estates are inserted in a planimetric urban design with form and function of a leaf: exploiting local and renewable resources, it uses active systems for the production of energy and passive technologies to reduce $\mathrm{CO}_{2}$ emissions [2].

From the formal point of view, the ribs and the margin of the leaf correspond to the viability (traffic): the main rib is dedicated to the soft mobility, the secondary ribs and the margin of the leaf to the traditional roads. The foil corresponds to the built lots and urban greenery. The formal configuration of the leafy neighborhood is integrated in full compliance with existing structures and enhancing the environment. 


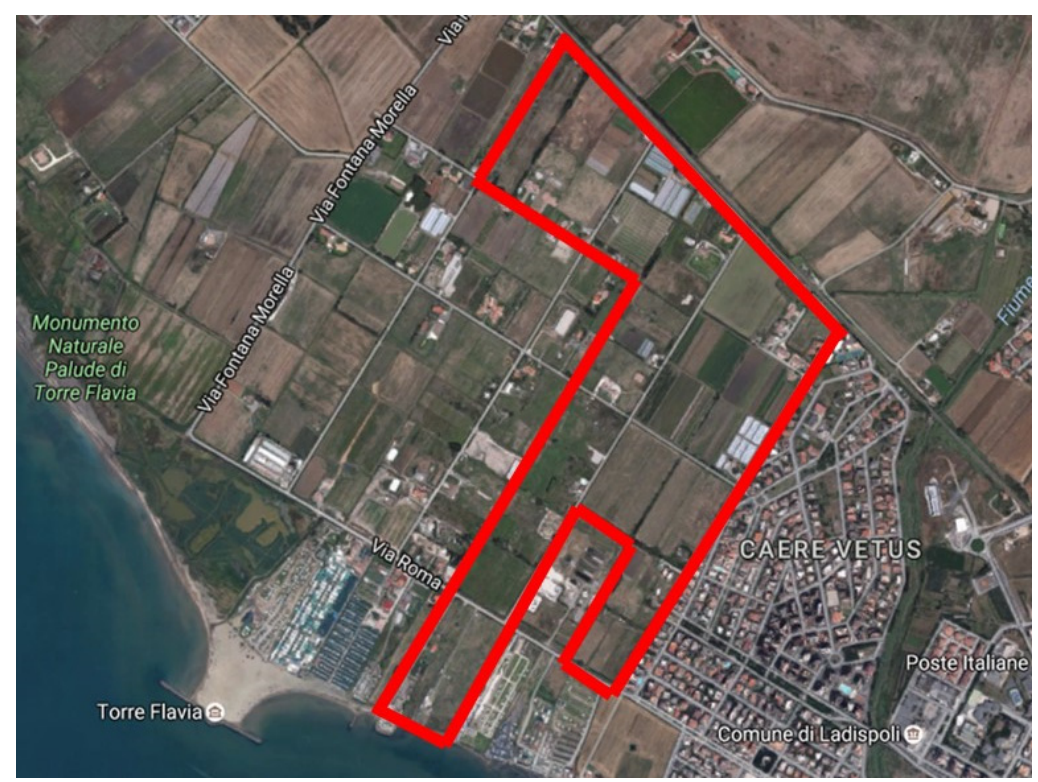

Figure 2: Intervention area.

The building volumes are organized into the ring road formed by the imaginary border of the leaf, and they delimit a large central area destined to green spaces, play areas for the youngest and areas for outdoor sports, walking and cycling routes. These spaces, public and private, give shape to a connective tissue of complex public relations, dominated by a dense network of walking and cycling routes that goes along neighborhood.

The open spaces are an essential factor for understanding the neighborhood, as they represent mainly the space of relationships and physical and mental wellbeing [3]. The area identified develops near the purification plant and the ecological island town of Ladispoli; currently in the area there are farmland, fallow fields, some scattered rural and residential buildings, and areas which are facing a substantial state of deterioration such as driveways connections. This situation highlights the need for an urban renewal plan aimed to promote the area through the insertion of some utilities even to nearby locations. An area dedicated to the elderly and others, including 16 short residential blocks to accommodate a total of about 1536 people, has been designed in respect of planning indices related to social-residential building construction. It has been calculated to resettle, per resident, $18 \mathrm{~m}^{2}$ of minimum allocation for the equipment of public interest as required by D.M. 1444/68, for a total of $27,648 \mathrm{~m}^{2}$ distributed as follows:

- $\quad 6.912 \mathrm{~m}^{2}$ for school construction;

- $\quad 3.072 \mathrm{~m}^{2}$ for facilities;

- $\quad 3.840 \mathrm{~m}^{2}$ for public parking;

- $\quad 13.824 \mathrm{~m}^{2}$ for green spaces.

The studied area is the mainly residential one (the intervention is $297,600.65 \mathrm{~m}^{2}$ ), with the purpose of identifying the best placement for buildings and green areas in the existing context, and for a more than satisfactory level of quality of life of all its inhabitants, especially the elderly (Fig. 3). 


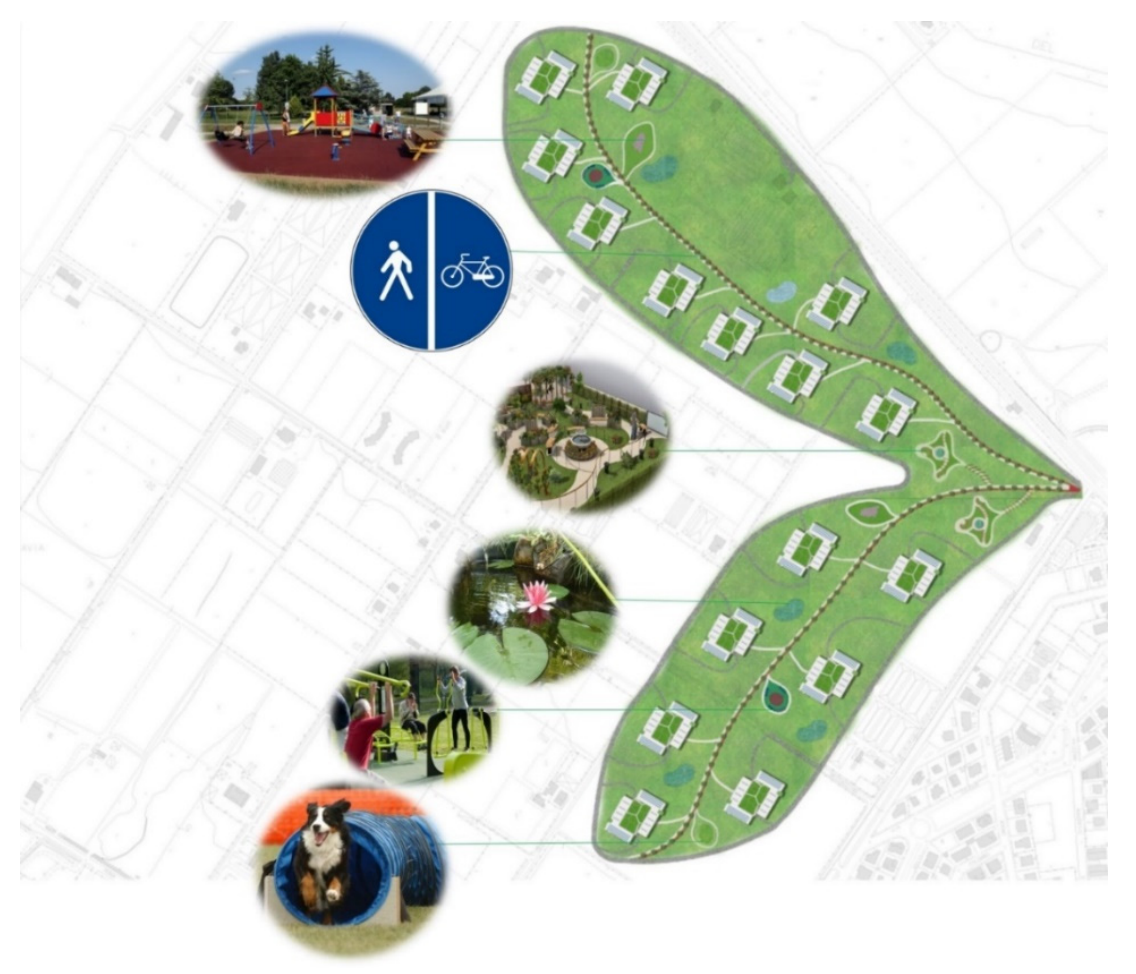

Figure 3: Functional zone of the zero-energy neighborhood.

\subsection{NZEB}

The project concerns a four-storied residential complex consisting of two L-shaped buildings which housing in total twenty-four apartments of $105 \mathrm{~m}^{2}$, potentially divisible into two units, for a total of 48 homes; this is the so called "life time home"; i.e. a flexible apartment able to fulfill the changing requirements of people during their life [4]. On the ground floor are located the commercial activities, the entrance to the residences through elevators and stairs, areas for common indoor activities and a technical room, while parking for both cars and bicycles are in the basement. On each residential floor a small space has been added as a greenhouse, to offer each tenant the opportunity to grow plants near his home (Figs 4 and 5). In a society, more and more technological and virtual, the horticultural therapy is, in fact, an opportunity to keep the contact with nature and, especially, to reach more physical and psychological

well-being through the stimulation of the senses of sight, touch, smell and hearing. The facades of the building are characterized by the presence of upcycled pallets with brise-soleil function to optimize the amount of sunlight, especially for facades facing south; these elements can slide along the metal structure that supports them, offering the ability to adapt to their needs, also giving a constantly changing configuration of the facade itself.

The project is an experimental prototype of dwelling Net Zero Site Energy Building (i.e. a building that produces at least as much energy as is required in a year its functioning) entirely eco-friendly thanks to the choice of special construction materials and 
well-integrated plants. The combination of active and passive solar systems allows making the structure a zero-energy building through the following measures:

- Inclusion in the facade of movable shading systems to limit the solar radiation in the summer;

- Use of a hybrid ventilation system to always guarantee the environmental comfort;

- Construction of a plant for the recovery of meteoric water, used for irrigation of crops in greenhouses;

- Solar energy used through the installation of a solar thermal and photovoltaic plant.

Each L-shaped building is in fact equipped with four rows by twenty-four photovoltaic panels each for a total of $48 \mathrm{~kW}$ for the whole house complex; four files each from solar collectors twelve, are also placed in coverage for a total of 960 liters of hot water per day.

The rainwater recovery system is designed to meet more than $50 \%$ of the water requirements which is about 364,680 1/year overall, mainly due to irrigation of the green areas of the court and small gardens. The entire complex plans to incorporate twelve underground tanks from $4 \mathrm{~m}^{3}$ each, the entire complex. Thermal hygrometric control of the apartments is made through multi-split systems air-air working as heat pumps. During the phase of executive design, following the geological surveys on the site, it will be possible to replace the heat pumps with geothermal probes with horizontal development.

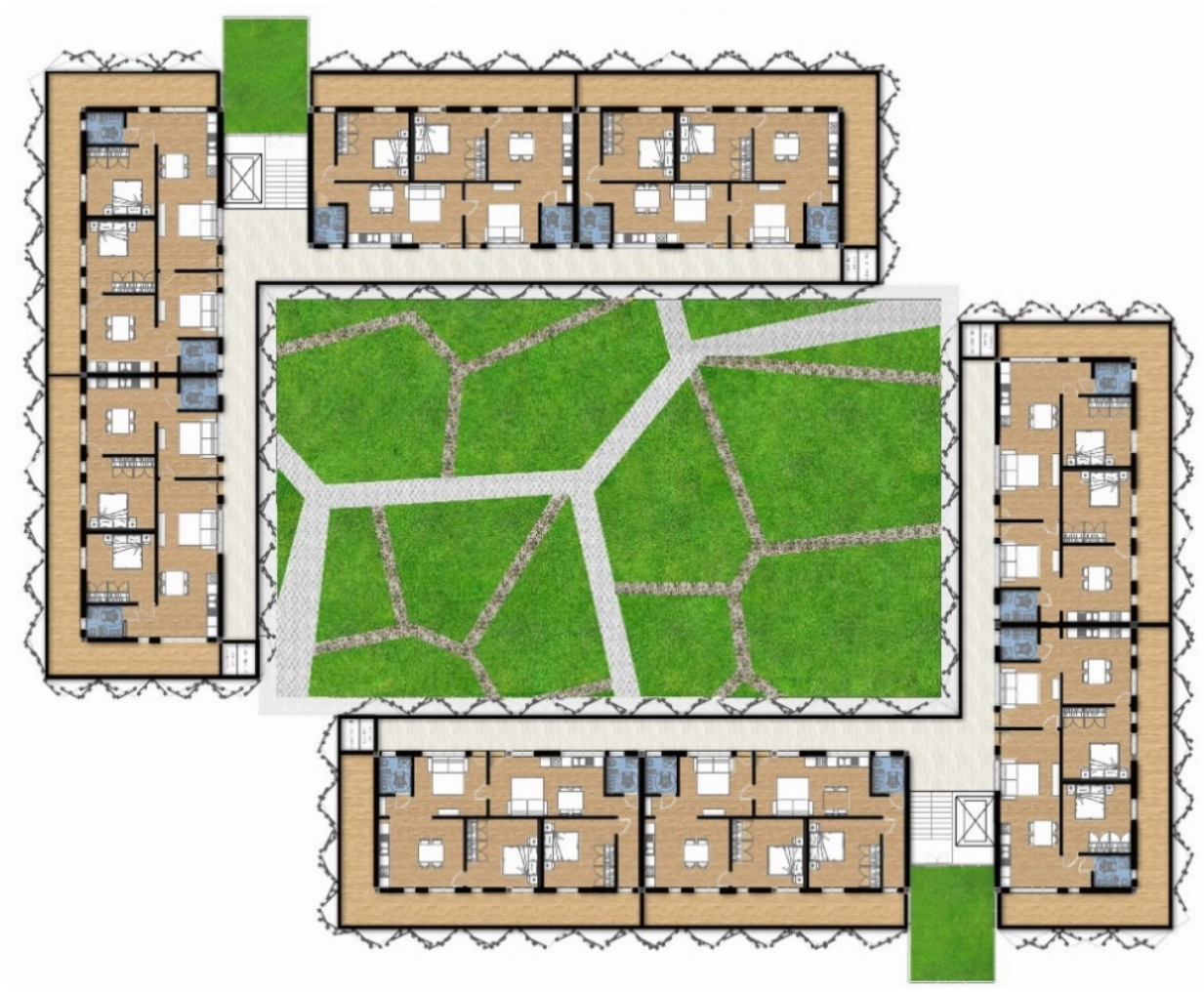

Figure 4: Plan of the First Floor of the housing complex. 


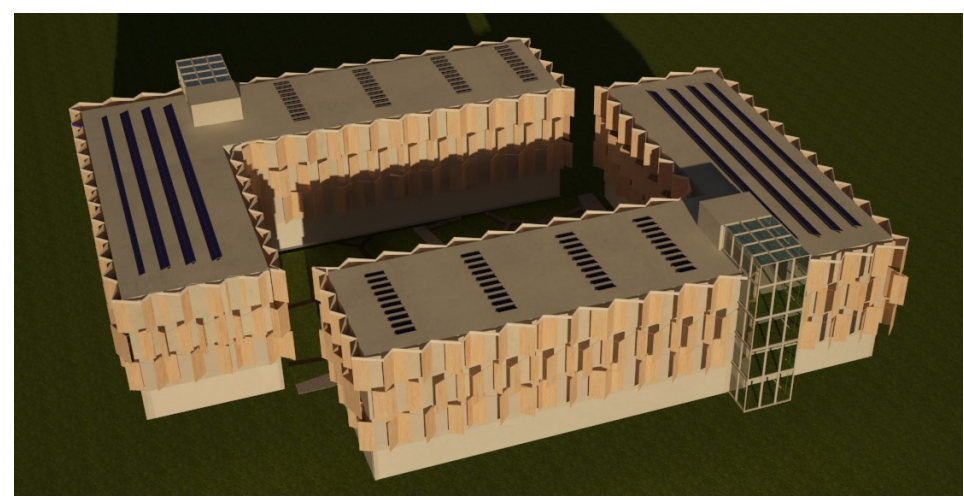

Figure 5: View of the building designed with the pallet component.

\subsection{Green spaces and equipped areas}

Urban green spaces improve human health and wellbeing. In fact, in the city, the themes of green as contact with nature and as areas for sports activity are inextricably linked. In addition to cycle paths, footing can be practiced in the green as well as many other sporting activities, both in indoor common housing spaces and outdoors, in plant and equipment to free enjoyment; for these reasons, some areas in the green has been designed with equipment to perform physical activity for free [5]. An explanatory board will indicate the full path and the available equipment. Children's areas are also designed. These have a floor covered with an anti-shock device to cushion the impact of any falls and reduce accidents and problems linked to safety in public play areas, respecting European regulations (UNI EN 1177). Inside urban green spaces are inserted artificial ponds to collect rainwater, which will be used for public park irrigation.

As a preventive measure to possible flooding, the small ponds can be connected directly to the sea proximity, with piping equipped with check valve.

A valid support for the elderly suffering from senile and pre-senile dementia is represented by the Alzheimer Garden, a green space protected to accommodate and satisfy the emotions of users. It was created to stimulate and preserve the remaining capacity, to delay the progression of the disease, to stimulate the remote memory of some users about previous activities like walking in the garden or grow vegetables, and to be able to reduce functional and cognitive deficits induced by dementia.

The garden is set up as a space for the senses, from touch to hearing and sight, through the insertion of colored and aromatic essences, and as a connective space given by paths and vegetation. The basic elements for the design of a Garden Alzheimer's are: water, rest areas, lighting, path, reference points, the fence, the vegetation.

The Alzheimer garden should be a guided tour, in which the people that are affected can move freely with or without their family, safely and without obstacles, on paved paths or green equipped areas, with a large number of benches and handrails (Fig. 6). Freedom of movement along with the ease of orientation, safety, sensory stimulation, the sense of serenity, are the core principles for a good project.

Another important element to be included as part of urban green is an area for dog agility. The latter is a sport that develops a good harmony between the dog and its handler and that, based on education and communication elements with the animal, promotes among citizens the concept of responsible management of the above-mentioned. 


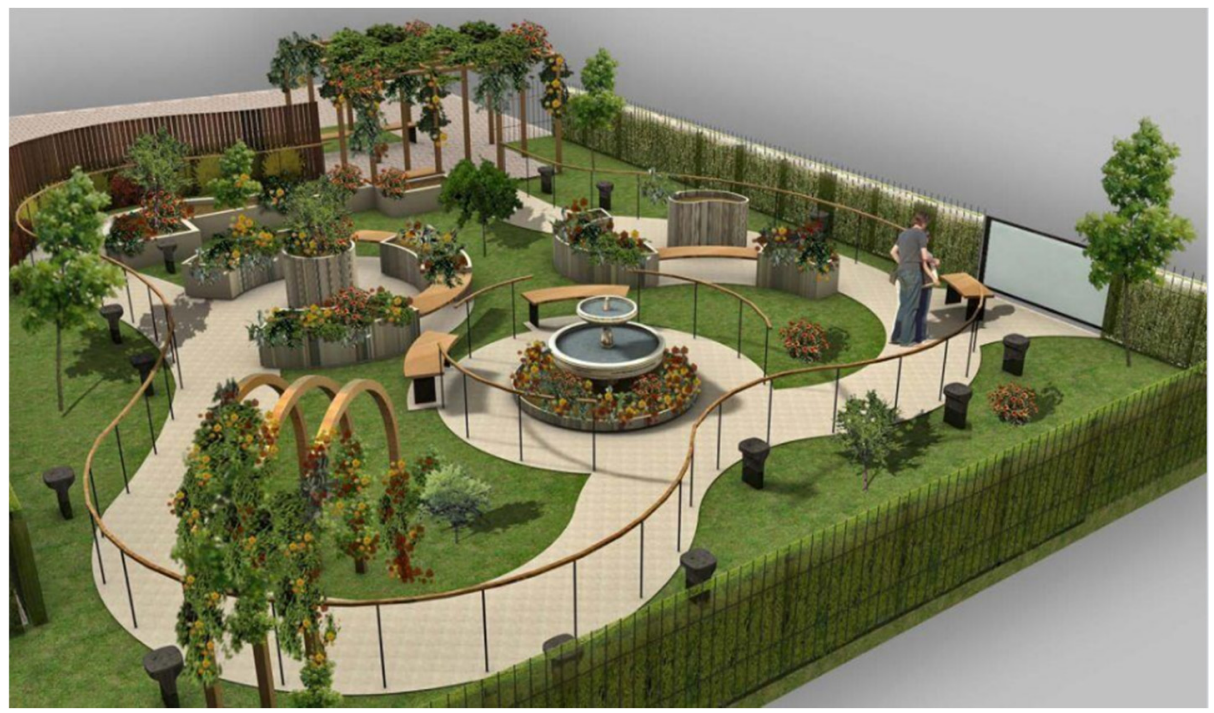

Figure 6: Alzheimer Garden.

It is also a social catalyst as it encourages going out and promoting opportunities for interaction and dialogue with other people, combating loneliness and isolation.

In conclusion, urban parks should be considered elements of connection and reconciling between the cement areas and natural areas. This goal can also be achieved in teaching and educational level, thanks to the construction of tracks and structures aimed to raise environmental awareness of citizens often rarely in direct contact with the natural heritage that we must preserve [6].

\section{SUSTAINABLE STRUCTURES FOR THE USE OF THE COASTAL ZONE}

The location of this environmentally sustainable structures project for a future port float, will be located in a sensitive area close to a SPA (Special Protection Area) "Natural Monument Marsh of Torre Flavia" and a historical landmark, the castle that is the symbol of the city of Ladispoli and after which the protected area is named.

The area forms the habitat of many species of migratory birds that use these marshy environments, where the silty clay soil is particularly rich in a thick organic substrate due to decomposition processes of plant species found there. In the stretch between the swamp and the sea, there are still some dune edges, subject to strong coastal erosion, which include priority habitats protected by the European Communities (Directive 92/43/EEC).

An analysis of the major human impacts that threaten the preservation of this protected area and high environmental value, emerges the building exploitation of the surrounding areas. In fact, although the current legislation don't allow the construction of building structures within the protected area, its conservation is hampered by the implementation of structures and infrastructure often made without proper environmental analysis that assess environmental impacts and lead for more environmentally friendly solutions for the protection of those specific ecosystems. The zone will include a parking lot, bathrooms with showers, a refreshment kiosk, and an information desk. The first one is shaded by photovoltaic trees, with six leaves each producing $12 \mathrm{~kW}$. These will provide charging points for electric cars and bicycles, as well as light of the whole park. 
To reduce the environmental impact of the service buildings a modular structure will be chosen composed almost entirely of wooden pallets dry assembled with metal joints. These pallets will be used for the external and internal cladding, as well as for the platform on which the whole structure rests without a need for foundations [7]. The pallets used for the exterior walls will be double so that insulating material can be inserted in one, and the water and electrical systems in the other. Two OSB panels will close the component both in the interior of the structure and on the outside. These OSB panel will form the outer facade of the building and will be waterproofed to ensure a good weather resistance. The buildings housing the toilets will each have an area of 16 square meters and will include two bathrooms symmetrical to each other. Each will also be equipped with two outdoor showers for summer use. A solar collector will be placed on the roof of each block bathroom and will heat the water autonomously. The kiosk will be about $250 \mathrm{~m}^{2}$ large and will comprise an area for food preparation, a storage area, a dressing room, an employee's bathroom, and two more for the customers. Using eight pallets, small fresh water pools can be added, usable both during the day and at night thanks to LED lighting (Fig. 7).

\section{NEW FLOATING PORT}

The coast of Ladispoli, currently devoid of jetties or piers, has been included in the Regional Plan of the ports, in 1998 by the Lazio Region, as a coastal area suitable for the construction of a new marina. It offers only two dry docks on the ground, with fixed and mobile cranes, one near the area of Torre Flavia and near the mouth of Vaccina ditch, "Porto Pidocchio"; it is a reference point for fishermen and boaters as it offers facilities for the beaching of the boats (Fig. 8). Currently, present garaging allows assistance and shelter for about 700 boats and offer minimal services such as water intakes, water slide, slipway, fixed crane up to 10 tons, mobile crane up to 4 tons, outdoor storage, repair engines, caretaking and toilet.

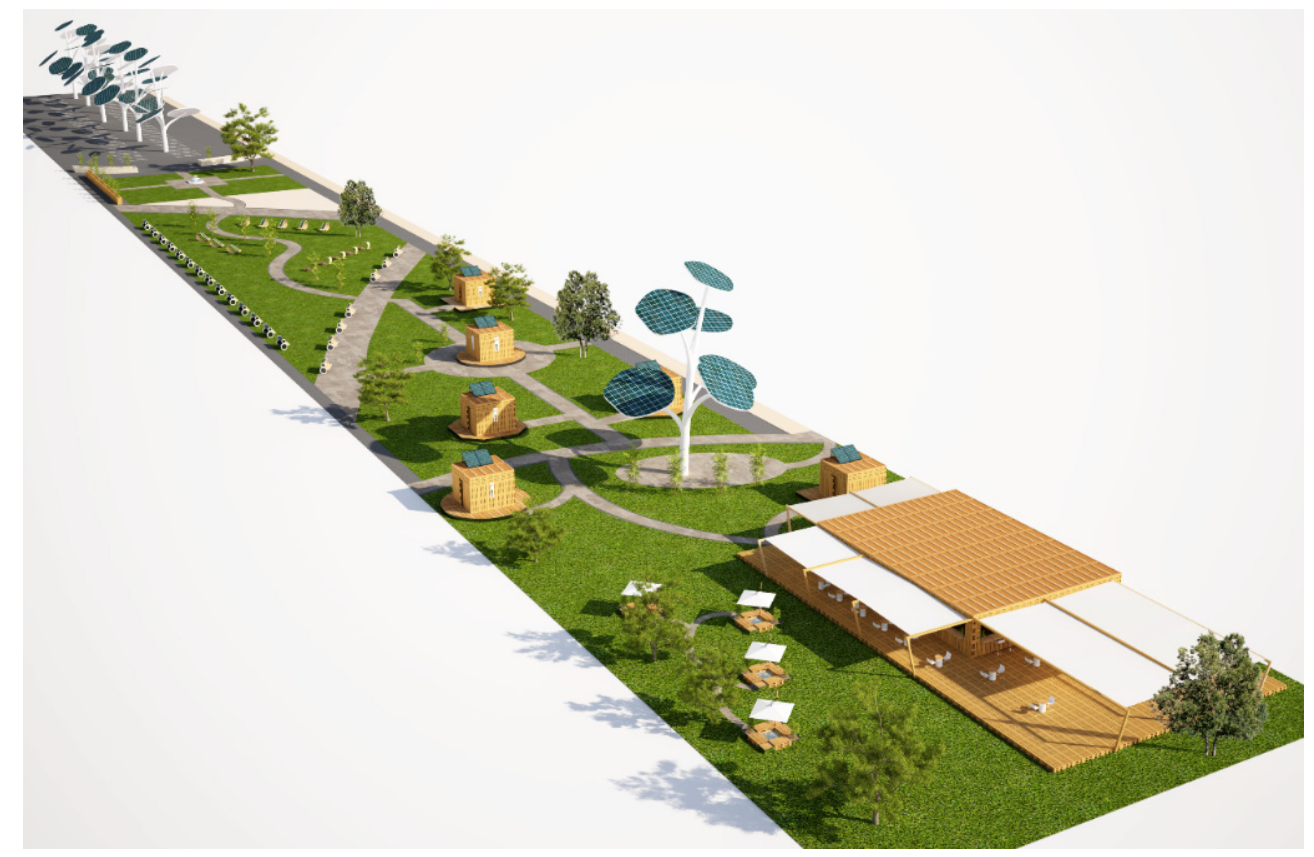

Figure 7: Service and connection area to the new port. 


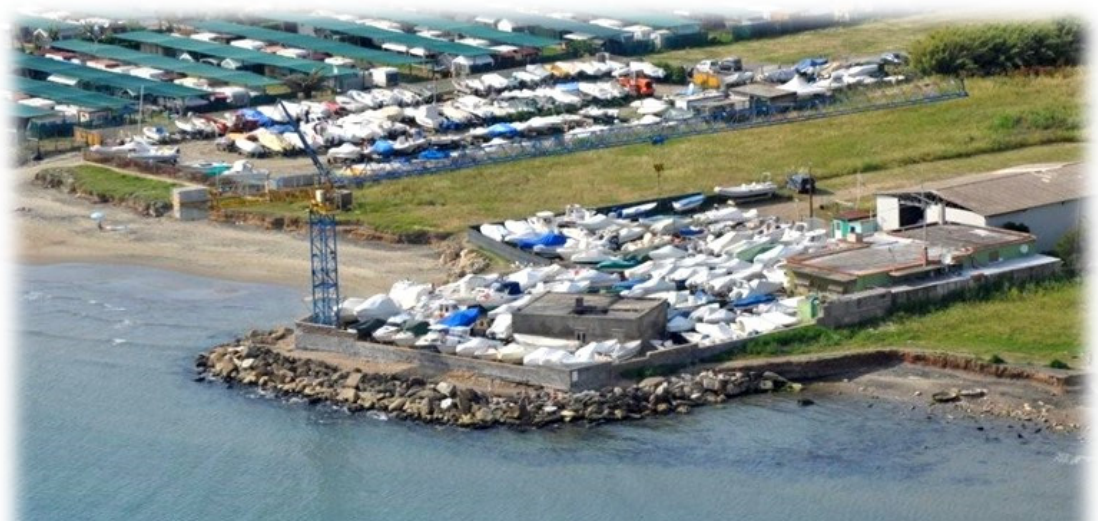

Figure 8: Current situation of the coastal zone.

The construction of a port in support of tourism and boaters would constitute an important occasion for the Municipality of Ladispoli in both economic and employment terms; it would also strengthen the local production system vocation in the regional water district. The local administration's goal, through the provision of a yachting infrastructure, is to ensure the reorganization of all the activities that settled along the coast, directly and indirectly connected to the sea and the redevelopment and sustainable use of the coast [8].

The new port is designed to accommodate 800 boats, including 400 for boats up to $10 \mathrm{~m}$ and 120 boats up to $12 \mathrm{~m}$, and to provide for a permanent and seasonal mooring, well-equipped docks with care and hospitality services for the whole year, shipbuilding services, surveillance and access to the network. Attention was placed on a floating port, also known as an island harbor, located about $200 \mathrm{~m}$ from the coast, in a location that does not absolutely threaten the oceanic Posidonia (Fig. 9). The island port is generally chosen when there is presence of sandy beaches with shallow waters where it's impossible to have within

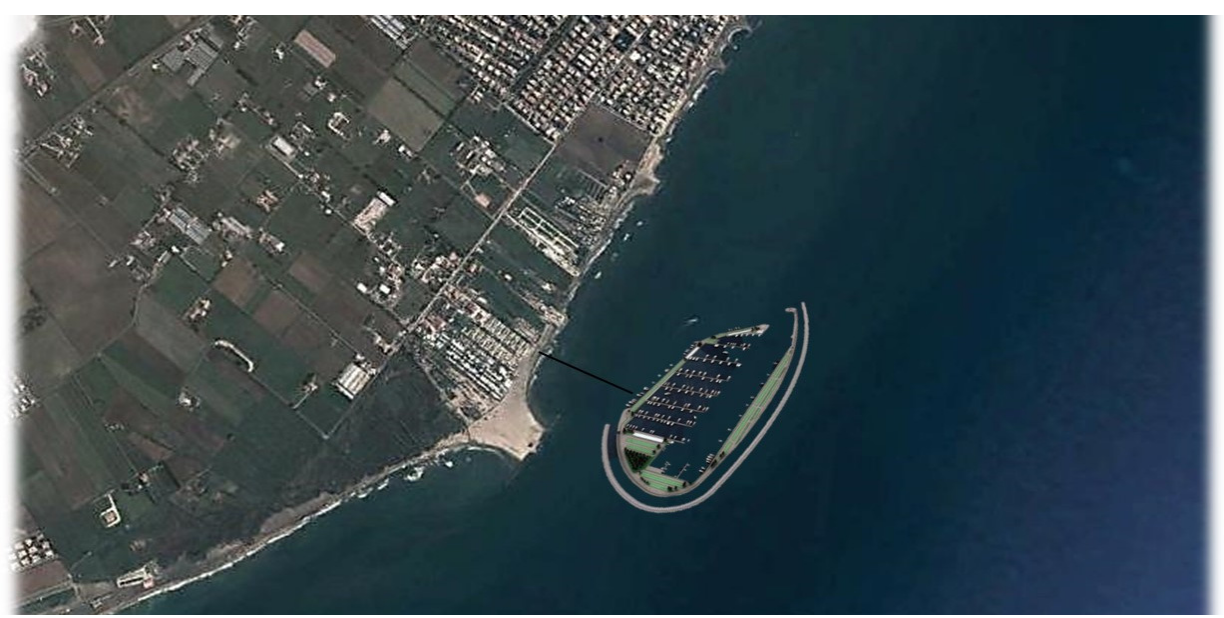

Figure 9: View of floating port. 
the port proper draft to let the ships in, consequently it became necessary to get away from the coast in order to build the plant where the bottom reaches adequate depth. This type of port also allows an easy removal. The chosen location, which is about 200 meters from the coast, given the present depth at the site (about 5 meters and above), is not exposed to significant sediment transport phenomena; the maximum significant transport depth is limited to about 4 meters. The port structure has a rounded shape conferred by that of the calm breakwater channel which acts like a heat sink of power and by an 800 -meter crowning dam constituted of a wave breaking system for stages of only 3.5 meters above sea level (against the 5 or 6 meters required by a conventional dam) and about 10 meters wide on the water surface.

The $90 / 95 \%$ of areas inside the breakwater dam are of floating nature.

The floating pontoons allow the mooring of boats both recreational and commercial, fishing, coastal look, moorings hydrofoils, etc. The realization of such a dam involves the handling of about 12,000 boulders from 5 tons each, obtained locally; for further reducing environmental impact of the breakwater dam, artificial stones, of special form that assume the aspect of local rocks, can be used in case of the absence of natural ones. The outflow takes place both through the interstitial porosity of the artificial boulders placed at the ends of the stilling basin, both through appropriately positioned channels in the external breakwater. The stilling basin acts as an energy sink. The access road, about 200 meters long, is carried out with pylons with a distance of 20 meters and is equipped with two vehicle lanes of 3 meters each, a bike path and two sidewalks for a total width of 12 meters.

Inside the port, it's possible to enter the charging stations for electric vehicles at parking lots for users and for service vehicles. The echo compatibility of the port structure is given by the production of energy from renewable sources; in particular, it is possible to insert photovoltaic panels and solar thermal collectors on the roof of the car parks and bus shelters on the roofs of buildings. The port, due to its location far from the coast, can also be powered through the installation of micro wind power systems that, needing a wind of constant direction and intensity superior to $5 \mathrm{~m} / \mathrm{s}$, will work only in limited periods of the year.

\section{CONCLUSIONS}

The increasing anthropic pressure on the Mediterranean Sea coast together with the issues of climate change, migratory flows and aging population, especially in Europe, requires an urgent rethinking of urban design criteria and governance of coastal cities. In the Italian peninsula becomes mainly urgent to rethink entire urban areas, designing them under imperative criteria such as environmental sustainability, social inclusion of the most vulnerable population sections, especially the elderly and young couples, and the strict respect of the architectural and archaeological constraints. The case study of the coastal city of Ladispoli, is particularly significant as it encompasses all the problems described above, amplified by the fact of being included in the metropolitan area of Rome, and to act as a "satellite district" of the biggest Italian metropolis. The proposed ad-hoc solutions can be taken out of context and replicated, so, in almost all the coastal urban areas of the North and South shores of the Mediterranean, with appropriate necessary precautions especially for energy supply of towns and cities themselves. In the manuals produced as output of the Great-Med research carried out within the European project ENPI-MED cooperation, and relevant to the Coast Zonal Management of the Mediterranean coast, some of the solutions proposed are contained. 


\section{REFERENCES}

[1] http://www.comune.ladispoli.rm.gov.it

[2] Cumo, F., Pennacchia, E. \& Piras, G., Urban cell connection strategies - sustainable mobilities and smart grid. SoURCE Towards Smart City, pp. 156-161, 2012.

[3] Dave, S., Neighbourhood density and social sustainability in cities of developing countries. Sustainable Development, 2009. DOI: 10.1002/sd.433.

[4] World Health Organization, Global Age-Friendly Cities: A Guide, 2007.

[5] Takano T., Nakamura, K. \& Watenabe, M., Urban residential environments and senior citizen's longevity in megacity areas: The importance of walkable green spaces. Journal of Epidemiology and Community Health, 56, pp. 913-918, 2002.

[6] Opdam, P. \& Steingrover, E., Designing metropolitan landscapes for biodiversity: Deriving guidelines from metapopulation ecology. Landscape Journal, 27, pp. 69-80, 2008.

[7] Cumo, F., Sferra, A. \& Pennacchia, E., Uso Disuso Riuso. Criteri e modalità per il riuso dei rifiuti come materiale per l'edilizia. FrancoAngeli, Milano, 2015.

[8] www.greatmed.eu 